\title{
A REFORMULAÇÃO DO SENTIDO DA VIDA A PARTIR DO ILUMINISMO SEGUNDO CHARLES TAYLOR
}

\author{
Michele Borges Heldt \\ Inácio Helfer \\ UNISINOS
}

\begin{abstract}
Resumo: Nos capítulos 18 e 19 do livro “As fontes do Self”, Charles Taylor busca entender as origens dos principais elementos formadores da identidade contemporânea, o que lhe conduz a uma análise histórica voltada para o fim da idade média e o início da era moderna. Apesar da diversidade dos elementos formadores da identidade moral encontrados nestes períodos, uma questão aparece incomum a todos eles, qual seja: o sentido da vida. $O$ presente artigo visa discorrer sobre este tema e mostrar, com Taylor, que essa questão ultrapassará a compreensão sobre os desígnios divinos, naturais, racionais e de cunho utilitário, - mas não sem arrastar consigo características herdadas de cada um desses períodos - e culminará em um novo modo de pensar. Esta nova concepção, na verdade, estaria diretamente relacionada com o desenvolvimento da capacidade dos indivíduos em aceitarem suas limitações e, com isso, buscarem entender sua irremediável tendência a atribuir sentido a todas as coisas.
\end{abstract}

Palavras-chave: Identidade contemporânea; idade média; sentido da vida.

\begin{abstract}
In chapters 18 and 19 of the book "Sources of the Self", Charles Taylor seeks to understand the origins of the main elements that form contemporary identity, which leads to a historical analysis towards the end of the middle ages and the beginning of the modern era. Despite the diversity of the elements that form the moral identity found in these periods, one question appears unusual to all of them: the sense of life. This article aims to discuss this topic and show, with Taylor, that this question goes beyond understanding about God's purposes, nature, rationality and utility - but not without drag together characteristics from each of these periods and culminates in a new way of thinking. This new conception, in fact, is directly related to the development of individual's ability to accept their limitations and, like this, seek to understand its irremediable tendency to attribute meaning to all things.
\end{abstract}

Keywords: Contemporary identity; medieval age; the meaning of life.

\section{Introdução}

Na obra "As fontes do Self", Taylor infere que as mudanças filosóficas são sempre decorrentes de profundas transformações dos pressupostos comuns e, ao mesmo tempo, articulam e promovem essas transformações, no sentido de que, a partir desses pressupostos, desenvolvem novas teorias capazes de engendrar novos conhecimentos e, consequentemente, novos valores. Dessa forma, as transformações filosóficas 
estão sempre em relação com as mudanças da própria cultura moral de seu tempo.

Segundo Taylor, durante essa transição a cultura moral é "frequentemente modificada; assim, o resultado é uma família de culturas morais parecidas, ou de certas características comuns a toda civilização com variações importantes entre nações e classes sociais". (TAYLOR, 2013, p. 395). Mas, mesmo com muitas variações, na análise de Taylor a cultura iluminista do século XVIII possuiria três pontos em comum encontrados na maioria das culturas ocidentais, quais sejam: valorização da autonomia, exploração dos sentimentos e ideia de bem viver ligada ao envolvimento pessoal.

\section{A individuação iluminista}

Durante o iluminismo desenvolveu-se uma cultura voltada para as necessidades individuais que, justamente por adquirirem muita importância, passaram a ser entendidas em caráter universal. Se antes o sacrifício em nome de Deus era visto como algo benéfico aos indivíduos, agora a eliminação do sofrimento e a autoexpressão assumem maior relevância. Essa nova cultura moral passou a relacionar-se também com outros setores da sociedade como a economia e a política, por exemplo. Disso se infere que a cultura iluminista não se disseminou somente a partir de novas formulações filosóficas, mas sim em decorrência de uma série de fatores relacionados, que juntos propiciaram o surgimento de uma nova cultura. Não seria possível apontar-lhe uma única causa, e é justamente por isso que Taylor (2013, p. 397) considera que "O movimento pela cultura é algo difuso e ambíguo, difícil de identificar e definir".

Além disso, o movimento que surge a partir da ascensão dessa nova cultura levou também a novas ideias e a um novo entendimento sobre o que seria "bem viver" que, nesse ponto, já não precisava estar relacionado com uma ordem providencial. Aliás, este é um elemento importante para o desenvolvimento dessa nova cultura, pois, ao contrário do período precedente ao iluminismo, neste a dimensão espiritual da vida humana não precisava mais fundamentar-se na existência de um Deus. Fatores oriundos dessa mudança cultural como a disseminação da ciência e da educação, entre outros, contribuíram para o crescimento da descrença religiosa porque, segundo Taylor (2013, p. 402), seus defensores em geral simplesmente consideravam ponto pacífico que a crença religiosa é irracional e pouco esclarecida ou anticientífica".

Entretanto, o fator determinante para que ocorresse tal mudança foi que os indivíduos não sentiam mais que a dimensão espiritual de suas vidas ficava incompreensível ao se supor a inexistência de um Deus que, até então, 
esteve ligado às únicas fontes morais que tais indivíduos podiam conceber. Nesse sentido, a proposta de Taylor é que, antes de tudo, se busque conhecer a perspectiva espiritual que se articula por detrás da crença, visto que algo somente se torna um bem para o indivíduo em detrimento daquilo que para ele é ruim. Seguindo esse raciocínio, precedida por um período de caos, a ordem passa a ser um bem para os indivíduos e esse bem, interiorizado, isto é, reconhecido genuinamente como algo importante e bom, torna-se uma fonte moral.

Por outro lado, uma ordem perfeita é algo que as pessoas não conseguem conceber plenamente, mesmo que se tenha um conceito sobre a imperfeição. É exatamente nesse ponto que a ideia de perfeição escapa para o transcendental, na medida em que não encontra nenhuma representação no mundo real. Assim, a ideia de uma ordem perfeita não pode ser separada da noção do divino, na medida em que só pode ser concebida de tal modo.

Segundo Taylor (2013, p. 404) “(...) é justamente esse inabalável enraizamento na crença que nos parece estranho hoje. Até nas sociedades em que a maioria das pessoas professa alguma crença em Deus ou num princípio divino, ninguém considera óbvia a existência de Deus". (TAYLOR, 2013, p. 404). Já os nossos antepassados, em geral, não tinham problemas com isso, justamente porque as fontes que eles podiam imaginar tornavam a descrença algo inconcebível. Atualmente, porém, temos outras fontes possíveis e, se de um lado isso nos permitiu sair da crença dogmática e expandir nossos conhecimentos racionais e científicos, de outro, fez com que certos princípios éticos que antes eram inquestionáveis se tornassem obsoletos.

\section{Fontes morais alternativas}

Essa mudança de valores indica que a moralidade não é algo imutável, mas sim algo cíclico, que além de se modificar ao longo do tempo, também contém em si uma diversidade proveniente da história e da pluralidade cultural. Nesse aspecto, apesar de estarem em lados opostos comunitaristas e liberais - Taylor aproxima-se de Berlin (2015) ao entender que os valores produzidos pelos indivíduos não são conciliáveis em uma única estrutura fixa e, por isso mesmo, o pluralismo é algo necessário para que haja evolução nas fontes morais. Inclusive Taylor (2013, p. 405) sugere que "quem sabe se outras transformações das fontes morais disponíveis não poderiam alterar todas essas questões de novo de forma irreconhecível!".

No entanto, o termo evolução, para Taylor, não significa, necessariamente, algo positivo. Disso se infere que, mesmo que a situação atual represente um ganho epistêmico ao nos apresentar novas alternativas, isso de modo algum significa que tenhamos alcançado um conhecimento verdadeiro, pois do mesmo modo que houve uma mudança radical em alguns 
conceitos que há poucos séculos pareciam absolutos, isso pode ocorrer de modo muito mais rápido nos dias de hoje, não somente pelos avanços da ciência e da tecnologia, mas também por conta de uma profunda mudança cultural.

Essa é a mudança cultural que temos de entender. A secularização não surgiu somente porque as pessoas adquiriram uma educação muito mais abrangente e porque a ciência progrediu. Isso teve algum efeito, mas não foi decisivo. O que importa é que grande número de pessoas pode perceber fontes morais de um tipo bem diferente, que não pressupõem necessariamente um Deus. (TAYLOR, 2013, p. 405).

As fontes morais alternativas que começaram a surgir no período renascentista e que definem, de certo modo, o panorama atual, brotaram de duas principais vertentes ${ }^{1}$, quais sejam, o desenvolvimento da capacidade racional, de expressão e de articulação dos indivíduos, e outra vertente mais profunda, ligada aos desejos, sentimentos e afinidades de cada um. Daí a aceitação do desvinculo das crenças religiosas, porque não bastava que os avanços da ciência mostrassem aos indivíduos outros caminhos além dos dogmáticos, mas eles próprios precisavam se livrar da submissão ao dogma para assumir o controle de sua própria racionalidade. Somente a partir desse ponto, isto é, dos avanços da racionalidade aliados a uma mudança cultural decorrente do desejo de emancipação dos indivíduos, é quase abriu espaço para novos valores morais que, consequentemente, arrastaram consigo novos bens de vida, que foram adquirindo maior importância e aprovação na medida em que tal mudança cultural foi ocorrendo.

Contudo, para que Taylor consiga fundamentar a sua tese sobre as fontes do nosso self, ele ainda terá que buscar entender porque certos bens de vida, em determinados períodos da história, se tornam mais proeminentes que outros na medida em que várias possibilidades se apresentam de forma simultânea.

É claro que o desenvolvimento subjacente de formas sociais, econômicas e políticas desempenha um papel; os primeiros estágios da ascensão do capitalismo e do Estado burocrático

\footnotetext{
${ }_{1}^{1}$ Nessa passagem, Taylor refere-se especificamente ao racionalismo e ao naturalismo, visto que desses dois movimentos originaram-se muitas outros. Em oposição ao racionalismo, baseado unicamente na razão para explicar a realidade do mundo, surgiu o empirismo, que ao ressaltar a importância do aprendizado por meio da experiência, tentativa e erro, proporcionou grandes avanços no campo científico. Já o naturalismo, em oposição direta ao sobrenatural, ou seja, ao dogmatismo religioso, entendeu o homem como uma criação da natureza e não de um deus, abrindo espaço para a compreensão dos seus instintos e desejos como traços de sua natureza animal, o que posteriormente propiciou o surgimento de outras correntes, voltadas para a compreensão das necessidades humanas.
} 
moderno, por exemplo, foram cruciais para a história que estamos acompanhando, mas jamais podem oferecer razões suficientes. O resultado depende crucialmente do tipo de cultura moral com que essas formas se entrelaçam (TAYLOR, 2013, p. 408).

Taylor, assim como MacIntyre (2004), sabe que as sociedades contemporâneas possuem características complexas e que a identidade moderna se originou de diversos fatores em conjunto, internos e externos. É uma articulação de valores morais, econômicos, sociais, culturais, estruturais, etc. Entretanto, como não é possível fundamentar uma teoria baseando-se em infinitas fontes, Taylor procurou direcionar sua pesquisa para três direções que, em sua análise histórica, aparecem e se mostram fundamentais, a saber: a crença religiosa, o desenvolvimento da razão e a natureza.

A primeira delas é de origem dogmática, portanto não requer fundamentação lógica. Já sobre as demais (razão e natureza), deve-se buscar entender e definir em que consiste a dignidade inerente aos indivíduos enquanto seres racionais e expressivos ou, em outras palavras, se a fonte de nossa consciência moral, que nos permite ultrapassar os instintos e agir com responsabilidade e alteridade para com os demais é de origem natural, racional ou divina?

Deveras, essa é uma questão extremamente complexa e que há muito acompanha a Filosofia, mas, para Taylor, de certo modo essas três vertentes estão relacionadas. Essa relação remonta às filosofias como a de Descartes, por exemplo, onde a capacidade de raciocínio dos indivíduos é entendida como uma dádiva de Deus aos homens. "É minha consciência de ser imperfeito, algo com que deparo inevitavelmente no estado de dúvida, que Descartes vê como inseparável de minha ideia de um ser perfeito que, por outro lado, não posso ter a não ser que exista um Deus". (TAYLOR, 2013, p. 419). Nessa concepção, a não submissão de Deus ao mesmo tratamento dado aos demais objetos de estudo da ciência não é entendida como um problema a ser resolvido, mas sim como um entendimento acerca da própria natureza da razão humana e de suas limitações.

Do mesmo modo se pode citar Spinoza, que atribuía os movimentos da natureza e do mundo material "ao fundo infinito da matéria", a qual se refere a uma única substância que em última análise seria o próprio Deus, na medida em que é em si e se concebe a si mesmo, isto é, aquilo cujo conceito não necessita de algo outro para se desenvolver.

Nessa mesma linha pode-se citar também Schelling, que concebe a natureza como uma totalidade viva, ou uma manifestação externa da razão em sua totalidade, que se desenvolve por força de sua dialética interna, proveniente do pensamento divino.

Enfim, Taylor percebe os elementos oriundos da fé religiosa, ou melhor, de uma mutação dessa forma de crença no cerne, tanto do naturalismo como do 
racionalismo, e assim entende que essas três vertentes estão irremediavelmente interligadas, mesmo que elas tenham assumido posições opostas ao longo da história, o que teria gerado uma “(...) visão superficial (...) de que a secularização deriva inteira e naturalmente do progresso da ciência e da razão". (TAYLOR, 2013, p. 418).

\section{O surgimento do iluminismo radical}

Dos preceitos da filosofia racionalista surgiu o iluminismo radical. No entanto, este se tornou bem mais racional que a filosofia cartesiana, na medida em que considera existente somente aquilo que a evidência mostra à razão, abstraindo qualquer visão relativa a fundamentos morais e espirituais. Essa passagem de Descartes ao iluminismo radical envolve uma mudança naquilo que era considerada a natureza e o lugar da razão, e foi nesse ponto que o sentido da própria vida passou a ser reformulado. Isso porque, para Descartes, apesar de somente se poder afirmar a existência daquilo que pode ser provado (o método cartesiano), ou, em outras palavras, ter certeza sobre a verdade das coisas em contraposição a crenças impostas e não justificadas, o pensar acerca de algo é sempre o primeiro passo no processo de conhecimento deste.

Partindo dessa premissa, Descartes chegou a algo que não podia duvidar: o fato de que ele estava duvidando. Ele não teria como duvidar que estivesse duvidando, pois assim ele só confirma que está duvidando. Eis aí a primeira certeza: duvido, logo existo. Porém, duvidar é um modo de pensar, então: "Penso, logo existo", que significa: penso, logo tenho consciência de mim mesmo, ou penso, logo sei, ou penso, logo tenho consciência, ou penso, logo sei algo que é certo.

Vale ressaltar que essa certeza, a certeza cartesiana, não é a certeza da existência de um corpo, ela é sim a certeza da existência da mente, não do cérebro, mas da consciência que, de acordo com Descartes, é diferente da existência do corpo: sabemos que as pedras não pensam, mas existem. Entretanto, a existência de que fala Descartes não se refere à existência dos objetos inanimados no mundo, tão pouco dos animais irracionais, e nem mesmo das crianças pequenas que ainda não adquiriram consciência sobre as coisas. A existência de que fala Descartes está diretamente ligada com a consciência de si, e esta, está relacionada com a reflexão que gera um saber real. Ou seja, se somente os seres humanos não existissem no mundo, as outras coisas (pedras, montanhas, rios, animais, etc.) obviamente continuariam existindo. Mas a existência de que fala Descartes está relacionada com a forma como os indivíduos percebem as coisas no mundo, isto é, a questão levantada por ele se refere à verdade das coisas e se a existência delas condiz com a forma como os indivíduos a percebem, inclusive a si mesmos. 
Esse modo de pensar cartesiano - que esteve em voga durante boa parte da idade moderna - ainda vincula a razão e os valores morais no pensamento, enquanto entende o mesmo como origem primeira de todo o saber, cuja capacidade nos é dada pela providência divina. Entretanto, apesar de colocar Deus no fundamento de sua filosofia, Descartes abriu caminho para um modo de pensar que não mais precisava da presença do divino para fazer sentido. É por isso que Taylor diz que a passagem da filosofia cartesiana ao iluminismo envolve uma mudança no que antes era considerada a natureza moral da razão, porque foi justamente a partir da filosofia de Descartes que a presença de um Deus no cerne de tudo passou a não ser mais necessária. "O iluminismo radical parece ter acreditado mais intensamente ainda nos frutos benéficos da compreensão racional. Estando libertados da confusão criada por princípios morais errados, da superstição e dos costumes provincianos, somos realmente capazes de ver o quadro todo, de conceber adequada e imparcialmente o bem universal" (TAYLOR, 2013, p. 426).

\section{Homogeneização de valores e utilitarismo}

Foi nesse período pós Descartes que ocorreu a cisão entre os valores morais e a racionalidade, que a partir desse momento passou a ser entendida como algo totalmente desvinculado de crenças morais. A partir daí, passou-se a acreditar que "Num mundo adequadamente organizado, em que a felicidade humana fosse mais bem servida, a felicidade de cada qual consistiria na felicidade de todos e até conduziria a ela". (TAYLOR, 2013, p. 426). Não que a moralidade tivesse perdido a sua importância, mas agora, aquela pluralidade de crenças que Descartes havia observado em suas viagens e que serviam de fundamento não justificado para uma série de valores morais que culminaram, por vezes, em verdadeiras atrocidades, não podia mais ser aceita: para o bem de todos, era necessário validar por meio da fundamentação lógica e racional toda e qualquer crença, para que fosse, dessa forma, justificada.

Um exemplo dessa concepção, no campo jurídico, é a teoria pura do direito, proposta por Kelsen (2009), a qual propõe o desenvolvimento de uma ciência do direito enquanto coloca o conhecimento jurídico como objeto de estudo científico. Dessa concepção, aliás, derivou-se o positivismo jurídico, cujos requisitos para verificar se uma norma pertence ou não a um dado ordenamento jurídico independem de critérios decorrentes de outros sistemas normativos como moral, ética ou política, por exemplo.

Segundo Taylor, a partir dessa fundamentação racional e também da homogeneização de valores, acreditou-se que todos os indivíduos compreenderiam e agiriam de acordo com essa harmonia, buscando a sua felicidade naquilo que fosse bom para todos. Um outro exemplo encontra-se também na filosofia hegeliana que, com base nos preceitos da Lógica, descreve 
o caminho percorrido pela consciência, em síntese, da seguinte forma: inicialmente, a consciência é somente para-si, isto é, é somente um puro nada na medida em que não enfrenta nenhuma oposição em si mesma. Para que a consciência se desenvolva, ela necessita da diferença, e essa, ela encontrará no ser-outro. O ser-outro é a oposição oriunda de tudo que vem de fora da consciência mesma e a precede na medida em que se forma a partir de informações anteriores a ela. Mas quando a consciência estabelecesse uma identidade com este ser-outro, por meio da linguagem e dos conceitos, ela se torna consciência-de-si, na medida em que reconhece essa identidade oriunda da determinação exterior como verdadeira para si mesma.

Sendo cada um para si, enquanto não é o Outro, aparece cada um no Outro, e só é na medida em que o Outro é. A diferença da essência é por isso a oposição, segundo a qual o diferente não tem frente a si o Outro em geral, mas o seu Outro, isto é, cada um tem sua própria determinação só na sua relação ao Outro; só é refletido sobre si enquanto é refletido no Outro, e o Outro, do mesmo modo: cada um é assim seu Outro do Outro (HEGEL, 2012, p. 233-234).

Mas, para Taylor (2013, p. 427), “(...) uma coisa é descrever a motivação humana numa situação de harmonia já realizada; outra, bem diferente, é atribuir às pessoas de hoje um amor pela humanidade que as levaria a trabalhar pelo bem comum independentemente do custo para si mesmas". Nesse sentido, sua proposta é que se faça um resgate da verdadeira base da vida moral, pois considera que os seus pilares nada têm a ver com o bem-estar geral, mas sim com a busca de cada pessoa por sua felicidade individual, que pode, ou não, relacionar-se com a felicidade dos demais.

A descrição do homem lutando por necessidade para preservar e aumentar sua felicidade não é apenas o resultado correto da reflexão distanciada; é também a verdadeira base da vida moral. Precisa ser resgatada não apenas das falsas teorias explanatórias espiritualistas, mas também da falsa depreciação que sofreu nas mãos da religião e da metafísica, que conclamaram os homens a negar esses impulsos em nome de satisfações e bens puramente imaginários. (TAYLOR, 2013, p. 421).

Isso não significa que Taylor desconsidere o fundamento da vida moral baseado na busca e preservação do bem-estar comum, contudo, entende que esse fundamento sofreu distorções, primeiramente por parte de crenças religiosas, e depois pela influência do iluminismo radical.

Além dessa vertente, não se pode deixar de citar a visão utilitarista, que também exerceu forte influência nas fontes de nosso self atual, e que parte justamente do fato levantado por Taylor, de que os indivíduos desejam a 
felicidade e a ausência de sofrimento. "O princípio de utilidade é aquele princípio que aprova ou desaprova todo e qualquer tipo de ação de acordo com a tendência que pareça ter de aumentar ou diminuir a felicidade das partes cujo interesse está em pauta" (TAYLOR, 2013, p.416). No utilitarismo, o caráter de cada indivíduo é formado pelos acontecimentos e circunstâncias ocorridas ao longo de sua história, que o levam a contribuir para a felicidade geral, ou não.

Portanto, no utilitarismo as pessoas não são "boas ou más" por natureza, mas podem transformar-se em um ou outro, de acordo com o resultado de suas associações. Essa visão conduz ao entendimento de que os valores humanos não são oriundos da natureza, da racionalidade ou ainda da providência divina, mas sim como campos neutros que se definem a partir das inúmeras interfaces estabelecidas entre os indivíduos e o mundo a sua volta.

Em sua filosofia, Taylor admite a importância dessas articulações na formação da identidade humana, porém, tão pouco considera que o indivíduo possa ser inicialmente neutro. Pelo contrário, para Taylor, o indivíduo já parte de uma base referencial permeada de valores. Essa concepção de que a felicidade é o único bem realmente relevante e que, portanto, deve ser buscada incessantemente, aliada à ideia de neutralidade inicial dos indivíduos, fez com que a busca pela felicidade pudesse ser perseguida com mais eficácia também pelo uso da razão instrumental. No entanto, para Taylor (2013, p. 429) "essa mesma neutralização elimina os termos em que sua motivação moral poderia ser formulada e reconhecida" na medida em que uma consciência neutra, via de regra, não possui em si um ideal de felicidade, mas o constrói a partir de suas relações com o mundo.

Aliás, crítica semelhante Taylor faz também à teoria da justiça de Rawls (2000), visto que os princípios e critérios dos quais partem os indivíduos para a definição do que seria uma instituição social justa - mesmo os de liberdade e igualdade sugeridos por Rawls - se dão a partir de suas vivências e relações, e não de um estado de natureza hipotético.

Enquanto o fundamento da teoria utilitarista concentrou-se na busca pela felicidade e ausência de sofrimento, as bases do iluminismo calcaram-se em determinações universais que pudessem trazer benefícios a todos, o que acabou por se converter em materialismo, de onde derivou a ideia de harmonia de interesses entre os indivíduos enquanto sociedade, onde a realização de cada um, passa pela realização de todos. Mas, para Taylor, essa concepção de que, a partir de valores universais comuns a todos é possível estabelecer um fundamento moral que, tomado como base para as ações de cada um é capaz de proporcionar bem-estar a todos, na prática, também não funciona.

Talvez as coisas pudessem ser maravilhosamente harmoniosas numa sociedade perfeitamente engrenada, mas porque devo trabalhar hoje por sua distante realização, a expensas até de minha vida e felicidade? Talvez os seres 
humanos em geral sejam movidos pela simpatia, mas e se exatamente agora, em relação a esses adversários, eu não for? (TAYLOR, 2013, p. 434).

Disso infere-se que a busca pelo bem-estar e a ausência de sofrimento, por mais que uma sociedade harmoniosa propicie o alcance desses bens e seja, dessa forma, um ideal a ser seguido, não é algo que possa ser inteiramente universalizado na medida em que passa pela escolha de cada um. É por esse motivo que, para Taylor, o utilitarismo entra constantemente em contradição com sua base ética racional porque, ao passo que, para os utilitaristas todos os indivíduos estão sob o domínio da dor e do prazer, para a teoria moral baseada na razão, apesar de dor e prazer serem critérios de ação corretos, estes devem ser empreendidos, não pelo modo como nos afetam individualmente, mas sim como afetam a todos. Não que os indivíduos não possam buscar sua felicidade no bem-estar geral, ou ainda, que não possa existir uma harmonia coletiva decorrente de interesses em comum, mas a pergunta que cabe aqui é: porque as pessoas procurariam por isso?

Segundo Taylor, qualquer indivíduo que ousar pensar por si mesmo de modo sincero sobre essa questão saberá que as ações humanas não são orientadas exclusivamente com base no bem geral, mas que existem uma série de outros fatores que, articulados, influenciam o modo de pensar e de agir de cada um, e que as motivações morais desempenham um papel fundamental nesse processo. Contudo, a ontologia desenvolvida e implementada pelo iluminismo ao longo dos séculos - de que o bem-estar coletivo seja a principal motivação para as ações dos indivíduos, que somente devem se movimentar dentro das regras impostas a partir da análise racional- impede que os indivíduos reconheçam suas próprias fontes morais. “(...) Em sua maior parte, essas fontes morais subjacentes emergem apenas por meio da retórica da argumentação e, sobretudo, por meio das denúncias dos erros religiosos e filosóficos que trazem tanto sofrimento à humanidade" (TAYLOR, 2013, p. 436).

Assim, a partir dos erros cometidos em nome de crenças religiosas, formularam-se teorias críticas que pretendiam demonstrar aquilo pelo qual os indivíduos não se deviam mais deixar enganar. No entanto, a maior parte dessas teorias não foi capaz de demonstrar a origem real dessas crenças, e tão pouco explicar porque elas ganham tanta força em determinados períodos históricos a ponto de se tornarem quase indissolúveis e capazes de influenciar e manipular o modo de pensar até mesmo de uma sociedade inteira.

\section{Bens de vida como fontes morais}

$\mathrm{Na}$ análise de Taylor, um fator que se mostra sempre presente e que exerce influência direta sobre o pensar e o agir dos indivíduos (apesar de 
qualquer ideologia), são os bens de vida que se transfiguram em fontes morais. Mas, como para os utilitaristas a prática das ações deve ser sempre de acordo com a sua utilidade, podendo variar de acordo com o momento e as circunstâncias, nesse contexto torna-se muito difícil reconhecer claramente quais as fontes morais que realmente norteiam as ações dos indivíduos. Desse modo, "Como suas fontes morais não podem ser reconhecidas, elas são invocadas principalmente na polêmica. Suas principais palavras de força são de denúncia. (...) O marxismo é um exemplo excelente". (TAYLOR, 2013, p. 436).

Porém, quando se passa da oposição para o governo, torna-se evidente o quanto a perspectiva utilitarista é débil, visto que a construção de uma nova ordem requer não apenas o conhecimento daquilo que se é contrário, mas, principalmente, uma perspectiva dos bens de vida que se quer promover. A busca por felicidade sem esse conhecimento, de acordo com Taylor (2013, p. 437), “(...) pode levar a uma destruição estarrecedora do estilo de vida de uma sociedade, a um nivelamento e supressão de tudo que não se encaixa nessa visão afunilada". Para Taylor, uma teoria que se sustente é aquela capaz de não somente apontar os erros alheios e se desenvolver a partir disso, mas antes identificar e entender quais são as fontes morais que levam um determinado grupo ou sociedade a agir de certo modo. Somente assim é que uma concepção consegue ultrapassar o dogmatismo e/ou idealismo, e se torna algo plausível e mais próximo da realidade e do cotidiano das pessoas comuns.

Ela tem de dar um sentido renovado à noção de que as realizações comuns dos seres humanos têm um significado especial, de modo que alguém que vive para essas realizações de maneira clarividente e não distorcida está vivendo uma vida superior à de alguém que, digamos, inflige-se mortificações em nome de um ideal religioso. E, além disso, esse significado cria uma exigência universal de forma que, por exemplo, posso ser chamado a trabalhar por um mundo futuro em que essas realizações serão maximizadas, mesmo que eu não venha a ter participação direta nele. (TAYLOR, 2013, p. 438)

Uma nova ordem, por exemplo, não pode ser imposta simplesmente a partir de sua utilidade ou bem gerado para a maioria, mas somente será genuinamente aceita se cada membro dessa ordem sentir que ela está realmente em consonância com as suas próprias fontes morais, o que torna essa análise um tanto mais complexa porque, diferentemente da concepção de Rawls, uma ordem nunca será estabelecida de forma neutra ou totalmente racional, mas sempre a partir de um ponto de vista que é amplamente influenciado pelas fontes morais de cada um. Sob esse prisma, ao mesmo tempo em que Taylor faz uma inferência histórica às mudanças ocorridas com o declínio da idade média, ele propõe ao leitor uma reflexão sobre o sentido da 
vida na contemporaneidade, através da análise das transformações que as fontes desse sentido sofreram ao longo do tempo.

$\mathrm{Na}$ idade média, o sentido da vida era Deus, e todos os atos e pensamentos dos indivíduos deveriam estar voltados para os desígnios divinos, sob pena de perderem não apenas o sentido, mas a própria vida. Com o seu declínio e o surgimento de novas correntes filosóficas, também a vida adquiriu novo sentido. Uma dessas principais correntes foi o naturalismo, onde, ao invés do modelo teocêntrico, entende-se que são as leis naturais que regem a estrutura do universo e, consequentemente, o comportamento humano. A partir desse entendimento abriu-se espaço para as questões relacionadas tanto à parte física e fisiológica, quanto à psicologia e ao desejo humano. Nesse ponto, o sentido da vida não estava mais em viver de acordo com os desígnios divinos, mas sim em satisfazer essas necessidades naturais, outrora renegadas.

No entanto, essa mudança foi muito mais profunda do que se pode perceber inicialmente, porque o sentido da vida, que antes era universalizado, passou a ser cada vez mais individual, de acordo com as necessidades e desejos de cada um. Com isso, ao se tornar tão único e abstrato a ponto dos indivíduos já não conseguirem mais identificá-lo, o problema, que antes era de cunho dogmático, cedeu lugar a algo ainda mais complexo, que é a banalização da própria vida.

\section{Um retorno ao jardim de casa}

Segundo Taylor, os indivíduos devem buscar entender a sua verdadeira natureza, justamente essa que os leva a atribuir sentido a todas as coisas. É a partir desse entendimento que o vazio existencial provocado pela aparente falta de sentido dará lugar à valorização da vida cotidiana, com todas as suas conquistas e dificuldades. E assim, retornando aos primórdios da filosofia, à máxima "conhece-te a ti mesmo", Taylor sugere que talvez o sentido da vida seja simplesmente a própria vida.

Nesse sentido, uma das correntes filosóficas que Taylor considera ter auxiliado os indivíduos a retomar o seu questionamento sobre o real sentido da vida teria sido o naturalismo, porque "Ao refutar as calúnias contra a natureza, ao aceitar sem reservas a matéria e o desejo, finalmente lhes atribuímos toda a sua dignidade, e isso nos dá condições de perceber por inteiro o bem e o significado desses desejos" (TAYLOR, 2013, p. 440). Ou seja, para Taylor, o reconhecimento dos desejos comuns aos indivíduos os capacita a viver esse bem de maneira mais integral, uma vez que esse reconhecimento liberaria o desejo humano da depreciação promovida pelo dogmatismo religioso e o moralismo universalizado.

O desejo individual é um bem capaz de motivar os indivíduos, e a falta de reconhecimento desse bem é o que há de mais problemático, segundo 
Taylor. Nesse sentido, sua filosofia se aproxima bastante da filosofia de David Hume, pois, apesar de Hume se opor totalmente à religião e a boa parte da metafísica tradicional, o fundamento dessa oposição se dá muito mais no sentido de que essas concepções levam os indivíduos a sabotarem a sua própria natureza, entendendo-a como domínio neutro que se pode controlar, ao invés de buscar o autoconhecimento e, consequentemente, a autoaceitação.

Podemos considerar que Hume explora uma das respostas
possíveis à perda da visão providencialista do mundo. Se não
podemos mais pensar em nossas realizações comuns como
algo que adquire importância por ser parte de um plano
divino, podemos suprimir por completo a questão do
significado (embora continuemos a viver em função de uma
resposta a ele) e objetificar o reino natural com vista a uma
eficácia máxima. Essa é a resposta utilitarista. Mas também
podemos explorar uma forma de ver nossas realizações
normais como significativas mesmo num mundo não
providencial. O significado estaria simplesmente no fato de
elas serem nossas, de os seres humanos não terem como
evitar, em virtude da própria constituição delas, atribuir-lhes
um significado, e de o caminho da sabedoria envolver o
reconhecimento e aceitação de nossa constituição normal.
(TAYLOR, 2013, p. 442)

É dessa forma que Taylor se aproxima da filosofia de Hume, no sentido de que, não é porque não se vincula mais à vida humana um propósito divino, que ela tenha perdido o seu sentido, ou que ela possa ser reduzida a um simples acaso, produto de uma natureza totalmente neutra e imparcial, mas é justamente nos limites da capacidade e da vida cotidiana dos indivíduos que se encontra o sentido de sua existência. Nesse entendimento, a degradação da crença religiosa não deve servir para a produção de novas teorias sobre o assunto, mas, principalmente, para se poder viver a vida como ela é, sem medo.

Assim sendo, a ideia central da filosofia de Taylor é de que o ser humano é capaz de viver bem e de se desenvolver desvinculado de qualquer idealismo, estabelecendo articulações complexas e que, ao mesmo tempo, elevam a consciência humana ao mesmo patamar de esplendor outrora auferido a Deus, à metafísica e à natureza. Mas, por outro lado, Taylor também entende que "(...) os humanos são irresistivelmente levados a atribuir significados a certas coisas”. (TAYLOR, 2013, p. 445).

Entretanto, o objetivo da autoexploração proposto por Taylor não deve ser entendido como sinônimo de desprendimento, pelo contrário, deve ser entendido como envolvimento, uma aproximação do indivíduo com aquilo que ele realmente é. Porém, Taylor também não menospreza os avanços decorrentes das diferentes correntes filosóficas expostas no presente artigo, tampouco as crenças religiosas, mas ressalta que o objetivo mais importante 
dos indivíduos não deve estar voltado para a resolução de problemas filosóficos que simplesmente não nos estão disponíveis, mas justamente aceitar essas limitações como parte de nosso próprio ser, e a partir disso alcançar uma liberdade que outrora, com base nos primeiros moldes da filosofia e da religião, nos parecia inalcançável.

A libertação não é no sentido de uma remodelação maravilhosa, mas de uma volta ao jardim de casa, uma aceitação agradecida de um espaço limitado, com suas próprias irregularidades e imperfeições, mas dentro do qual algo pode florescer. A inspiração moral não vem da perspectiva de transformação, mas da duramente conquistada capacidade de cuidar desse espaço limitado. (TAYLOR, 2013, p. 444)

\section{Considerações Finais}

O objetivo central de Taylor em “As Fontes do Self” foi entender as origens das características formadoras da identidade ocidental contemporânea. Para isso, o autor empreendeu uma análise histórico-filosófica desde o período da idade média, passando pelo naturalismo, o racionalismo e o utilitarismo, até culminar no iluminismo radical. Ao analisar estes diferentes períodos, Taylor constatou que o dogmatismo religioso presente em toda a era medieval, e também no cerne dos movimentos naturalistas e racionalistas, levou séculos para se dissipar. A ruptura com o dogma religioso não ocorreu instantaneamente durante o iluminismo, mas já vinha ocorrendo há muito tempo, devido a uma profunda mudança cultural. A partir dessa mudança, o sentido da vida, que antes era voltado para o cumprimento dos desígnios divinos, passou a voltar-se para a busca do bem-estar comum. Entrementes, muitos movimentos que daí decorreram (como o materialismo, por exemplo) fracassaram porque, na visão de Taylor, o sentido da vida passa, antes de tudo, pela busca da felicidade pessoal, onde o indivíduo somente irá reconhecer as demandas provenientes do exterior, se estas corresponderem às suas próprias demandas. O problema que daí decorre é a falta de valores em comum, que é justamente aquilo que forma a identidade de qualquer sociedade. A identidade é algo que se constrói a partir da relação com o outro, e a falta desta, em última instância, conduz à desvalorização da própria vida, à indiferença, e ao total desrespeito ao próximo. Nesse aspecto, especialmente no tocante aos princípios contemporâneos de justiça, assim como Sandel (2005), Taylor defende o debate democrático como uma forma de reestabelecer estes valores em comum.

Além disso, Taylor propõe uma volta ao "jardim de casa", que representa um olhar para dentro de si mesmo e o reconhecimento de que faz parte da natureza humana viver em sociedade e atribuir sentido às coisas. A 
partir desse entendimento, Taylor sugere que se busque novas perspectivas que sustentem os bens de vida que envolvem o bem-estar comum e a vida em comunidade, com o propósito de não cairmos em uma espécie de individualismo radical.

\section{Referências Bibliográficas:}

BERLIN, Isaiah. As raízes do romantismo. São Paulo: Três Estrelas, 2015.

DESCARTES, René. Meditagões metafísicas. $4^{a}$ ed. São Paulo: Martins Fontes, 2016.

ESPINOSA, Baruch de. Ética. São Paulo: Nova Cultural, 2000 (Coleção Os Pensadores).

HANS, Kelsen. Teoria pura do direito. $8^{a}$ ed. São Paulo: Martins Fontes, 2009.

HEGEL, GWF. Fenomenologia do espirito. $4^{\mathrm{a}}$ ed. Rio de Janeiro: Editora Vozes, 2007.

MACINTYRE, Alasdair.Depois da Virtude. $3^{a}$ ed. São Paulo: Edusc, 2004.

RAWLS, John. Uma teoria da justiça. São Paulo: Martins Fontes, 2000.

SANDEL, Michael. O liberalismo e os limites da justiça. $2^{\mathrm{a}}$ ed. Portugal: Fundação CalousteGulbenkian, 2005.

TAYLOR, Charles. As Fontes do Self. São Paulo: Edições Loyola, $4^{a}$ edição, 2013.

Email: heldt.michele@hotmail.com

Recebido: $11 / 2016$

Aprovado: 01/2017 